Int. J. Plant Sci. 164(3):371-376. 2003.

(c) 2003 by The University of Chicago. All rights reserved.

$1058-5893 / 2003 / 16403-0004 \$ 15.00$

\title{
ADAPTIVE DIFFERENTIATION IN RESPONSE TO WATER STRESS BY EDAPHIC RACES OF LASTHENIA CALIFORNICA (ASTERACEAE)
}

\author{
Nishanta Rajakaruna, ${ }^{1}$ Gary E. Bradfield, Bruce A. Bohm, and Jeannette Whitton \\ Department of Botany, 3529-6270 University Boulevard, University of British Columbia, Vancouver, British Columbia V6T 1Z4, Canada
}

\begin{abstract}
Two edaphic races of Lasthenia californica sensu Ornduff (races A and C) grow in parapatry on a serpentine outcrop at Jasper Ridge Biological Preserve, California. The races occupy distinct edaphic habitats that have different water-holding capacities. We predict that the two races will show differentiation in reproductive strategies related to their response to water stress. In order to test this hypothesis, we performed a greenhouse experiment to characterize the reaction norms of the two races exposed to a gradient in water availability. We measured the response of five variables to the watering treatments: early survivorship, days to flowering, root/shoot dry mass ratio, total dry mass, and a measure of reproductive fitness, number of flower heads. We found that the races differ in their allocation patterns to roots compared with shoots and in days to flowering, indicating genetic differentiation for these traits. Race A consistently allocates relatively more biomass to roots while race $\mathrm{C}$ flowers earlier. However, the reaction norms of the two races for all nonreproductive traits are parallel, indicating that races do not differ in their plastic response to drought stress. The number of flower heads, our measure of reproductive fitness, did, however, exhibit differential response to water availability between the two races. Under low watering treatment, race C plants are able to maintain flower head production, while race A plants show a monotonic decrease in head production as water stress increases. Results indicate that race $\mathrm{C}$ plants are better adapted to drought; they are able to maintain a high reproductive output under low water availability. However, as the phenotype of race A is affected by drought, reproductive output decreases, as we would predict for plants that rarely experience drought in their natural environment.
\end{abstract}

Keywords: edaphic races, drought tolerance, Lasthenia, phenotypic plasticity, reaction norm, serpentine, water stress.

\section{Introduction}

Fitness depends on an interaction of the phenotype with the environment. When closely related sets of populations (e.g., species, subspecies, races) overlap in geographic distribution and occupy distinct habitat types, it is reasonable to hypothesize that each may achieve its distribution through differential relationships of relevant environmental variables with fitness, i.e., through differential adaptation (Wade and Kalisz 1990; Dudley 1996a, 1996b; Sultan 2001). Reaction norm data can be pertinent to studies of adaptation if it can be shown that populations differ in their fitness response to variables that are known to distinguish their habitats (Marshall et al. 1986; Schmitt et al. 1992; Schmitt 1993; Zhang and Lechowicz 1994; Dudley 1996a). An adaptive hypothesis remains tenable if individuals achieve higher fitness under the environmental conditions that best match their natural environment.

Species that occur under a range of water availability regimes may exhibit intraspecific differences associated with temporal or spatial heterogeneity in soil environments. A classic example of this phenomenon is wild oats, Avena barbata L., where different genotypes are characteristic of contrasting soil water

\footnotetext{
${ }^{1}$ Author for correspondence; current address: Department of Biological Sciences, Stanford University, Stanford, California 94305-5020, U.S.A.; fax 650-723-6132; e-mail nishanta@stanford.edu.
}

Manuscript received March 2002; revised manuscript received November 2002. environments throughout the Californian Floristic Province (Clegg and Allard 1972; Hamrick and Allard 1972). On a single hillside where conditions range from mesic to xeric, genotypes are found associated with particular habitats, and selection acts to maintain this distribution despite considerable gene flow (Hamrick and Holden 1979). Differential responses to water availability are thought to play a role in the ecological divergence of closely related taxa (Roy and Mooney 1982; Farris 1987, 1988; Aronson et al. 1993; Sultan and Bazzaz 1993).

Water availability is critical to the timing and extent of reproduction in chaparral communities (Chiariello 1989; Girdler 1999), and this is particularly acute on serpentine soils, where the extreme ionic composition further complicates water uptake. In serpentine environments, physiological stress results from low availability of water, high ionic content of the soil solutions, or a combination of both (Proctor and Woodell 1975; Kruckeberg 1984; Baker et al. 1992; Proctor 1999). These effects are exacerbated by high soil surface temperatures and the shallow, rocky nature of serpentine soils. On the serpentine outcrop at Jasper Ridge Biological Preserve, two edaphically differentiated races of Lasthenia californica sensu Ornduff (1993) (Heliantheae: Asteraceae) occupy distinct habitats that differ in $\mathrm{pH}$, cation exchange capacity, total ionic strength, sodium, magnesium, calcium/magnesium, and waterholding capacities (Rajakaruna and Bohm 1999).

A stable, abrupt transition zone exists between the contig- 
uous races, $\mathrm{A}$ and $\mathrm{C}$, on this serpentine outcrop. The two races can be distinguished by their flavonoid pigment profiles (Bohm et al. 1989; Desrochers and Bohm 1993), allozyme banding patterns, achene features (Desrochers and Bohm 1995), and sodium ion uptake physiology (Rajakaruna et al. 2003).

A recent phylogenetic study (Chan et al. 2002) assigns races $\mathrm{A}$ and $\mathrm{C}$ at Jasper Ridge to separate cryptic species, L. californica subsp. californica DC. ex Lindl. and L. gracilis (DC.) Greene, respectively. Population genetic studies of the two edaphic races (Rajakaruna et al., in press) indicate that both races are found in each of these closely related species, which may imply that racial characteristics have evolved in parallel in response to edaphic features. Because we are concerned here with potentially adaptive responses of edaphic races, we continue the traditional treatment of these entities as races at Jasper Ridge (Rajakaruna and Bohm 1999).

Gene flow and crossability estimates indicate that the races are reproductively isolated at Jasper Ridge (Desrochers and Bohm 1995; N. Rajakaruna and J. Whitton, unpublished manuscript). Race C plants occupy the upper reaches of the outcrop, an environment that is ionically more moderate than the lower reaches but tends to dry out more rapidly. Race A plants occur at the bottom of the outcrop, which is ionically more extreme but only dries out at the end of the growing season. Reciprocal growth studies conducted in the greenhouse using field-collected soils have shown that race $\mathrm{C}$ plants are unable to grow to reproductive maturity in the ionically extreme soils of race A plants (Rajakaruna and Bohm 1999). Field observations and greenhouse studies have indicated that the races may respond differentially to water stress. For example, race C plants consistently germinate $2-3 \mathrm{~d}$ and flower $7-10 \mathrm{~d}$ prior to race A plants. Faster growth to reproductive maturity may allow race C plants to avoid drought (Fox 1990; Aronson et al. 1992). Observations also indicate that the races differ in their biomass allocation patterns; race A appears to allocate more mass to roots than shoots, consistent with patterns often seen in plants growing under nutrient-poor, ionically stressed conditions (Kramer 1980; Grime 1994). Furthermore, toward the end of the growth season, race A plants are also exposed to drought, and the greater root/shoot ratio may be advantageous during the latter part of its life cycle.

In this study, we use populations of the two edaphically differentiated races of $L$. californica sensu Ornduff collected in distinct microhabitats at Jasper Ridge to explore their responses to water stress. While ionic stresses of serpentine soils are generally emphasized in the literature (Baker et al. 1992), we chose to explore the effects of water stress in isolation because available water for uptake is known to be critical in ionically harsh environments (Fitter and Hay 1987; Hughes et al. 2001). Furthermore, edaphic features are often correlated; for instance, soil moisture content is positively correlated with organic matter content, percent clay content, and soil porosity (Gaudet and Keddy 1995), and conclusive determinations of environmental tolerance for particular factors require controlled, single-factor studies (Sultan 1995). We hypothesize that adaptation to the differing water availabilities experienced by the two races will have produced differentiated responses to water stress. We predict that the two races will show differentiation in reproductive strategies related to their response to water stress. Specifically, we expect race $\mathrm{C}$ plants to be better adapted to severe water stress and to achieve higher fitness in this environment than race A plants. As race A plants generally experience severe water stress only at the end of the growing season, we predict that they will be less well adapted to long-term drought and will have lower reproductive fitness under these conditions. In order to test this hypothesis, we have performed a greenhouse experiment to characterize the reaction norms of the two races exposed to a gradient in water availability.

\section{Material and Methods}

\section{Description of Source Population}

Lasthenia californica sensu Ornduff, the common goldfields of California, is a spring annual found growing in a variety of habitats in the Californian Floristic Province. Cypselae for this study were collected from the serpentine outcrop at Jasper Ridge Biological Preserve, San Mateo County, California $\left(37.4^{\circ} \mathrm{N}, 122.25^{\circ} \mathrm{W}\right)$, located in the Mediterranean climate zone of coastal California. The serpentine outcrop is located at ca. $180-\mathrm{m}$ elevation, with mean summer temperatures of $20.1^{\circ} \mathrm{C}$, mean winter temperatures of $9.2^{\circ} \mathrm{C}$, total annual precipitation of $622.4 \mathrm{~mm}$, and a dry season of ca. $6 \mathrm{mo}$ (May-October, precipitation $<50 \mathrm{~mm} / \mathrm{mo}$ ) (Ackerly et al. 2002). At Jasper Ridge, L. californica germinates after the first significant rains in the late fall. The plants flower and set seed mostly by April or early May.

\section{Experimental Design}

Cypselae were collected from random plants along three previously established transects (Rajakaruna and Bohm 1999) and from plants found between the transects in order to sample plants growing in the range of microhabitats represented on the ridge. The area of seed collection represented ca. $60 \times$ $100 \mathrm{~m}$ of the serpentine outcrop. At least two flower heads from ca. 100 individual plants from both races were targeted, and the cypselae were pooled in large envelopes. From this pool of ca. 10,000-20,000 (each flower head has ca. 50-100 cypselae) mixed cypselae, 10 were randomly chosen to be sown on each pot.

Thirty pots $(4 \times 4 \times 4$ in $)$ were filled with potting mix (Terra Lite Soil Mix, W. R. Grace, Ajax, Ontario) and watered with tap water until the soils were saturated. The pots were moved to a dark, cold room for $3 \mathrm{~d}\left(5^{\circ} \mathrm{C}\right)$, after which they were moved to random bench locations in a growth chamber $\left(18^{\circ} \mathrm{C}\right.$ during the day, $13^{\circ} \mathrm{C}$ at night; humidity $55 \%-75 \%$; light $382 \mu \mathrm{Mols}^{-1} \mathrm{~cm}^{-2}$ ). Soils were brought back to saturation by adding $100 \mathrm{~mL}$ of tap water per pot, and pots were watered every $3 \mathrm{~d}$ with $100 \mathrm{~mL}$ of tap water. On the tenth day after sowing, the pots were randomly thinned to five plants, approximating field density. On the seventeenth day after sowing, three watering treatments were begun, with five pots per treatment for each of the two races.

In the high watering treatment, pots were watered every 3 d with $100 \mathrm{~mL}$ of tap water, maintaining soils at or near saturation. In the medium and low watering treatments, pots received no further water for a period of $6 \mathrm{~d}$ from saturation, at which time the soils were brought to field capacity by adding $100 \mathrm{~mL}$ of tap water per pot. Water content at field capacity 
Table 1

F Values from Two-Way ANOVAs of Race and Watering Treatment Effects on Five Response Variables in Lasthenia californica

\begin{tabular}{|c|c|c|c|c|}
\hline Variable & $\begin{array}{c}\text { Race } \\
(\mathrm{df}=1)\end{array}$ & $\begin{array}{l}\text { Treatment } \\
(\mathrm{df}=2)\end{array}$ & $\begin{array}{c}\text { Race } \times \text { treatment } \\
(\mathrm{df}=2)\end{array}$ & Total $R^{2}$ \\
\hline Survival & $0.19 \mathrm{~ns}$ & $2.14 \mathrm{~ns}$ & $0.54 \mathrm{~ns}$ & 0.19 \\
\hline Days to flowering & $7.1^{*}$ & $15.7^{* * *}$ & $0.13 \mathrm{~ns}$ & 0.62 \\
\hline Total dry mass (g) & $10.96^{* *}$ & $25.89^{* * *}$ & $0.73 \mathrm{~ns}$ & 0.73 \\
\hline Root/shoot dry mass ratio & $21.9^{* * *}$ & $9.4^{* *}$ & $0.6 \mathrm{~ns}$ & 0.64 \\
\hline Number of flower heads & $33.61^{* * *}$ & $53.33^{* * *}$ & $11.61^{* * *}$ & 0.87 \\
\hline
\end{tabular}

Note. All analyses based on sample sizes of 30 pots. $n s=$ not significant.

${ }^{*} P<0.05$.

** $P<0.01$

${ }^{* * *} P<0.001$.

was estimated by determining the relative water content of the soil 2-3 d after saturation when free drainage has completely ceased. From then on, the medium watering treatment consisted of adding $75 \mathrm{~mL}$ of water per pot every $3 \mathrm{~d}$, maintaining soils at or near field capacity for the duration of the experiment. In the low watering treatment, pots received $100 \mathrm{~mL}$ of water every $6 \mathrm{~d}$ to bring the soil to field capacity. The low watering treatment appeared to have a similar effect on both races, since a few plants from both races showed signs of wilting at the time of watering. On a few occasions, early in the experiment, low watering treatment pots required watering on the fifth day to avoid severe wilting and mortality of plants.

On the third week after germination, the temperature in the growth chamber was increased to $22^{\circ} \mathrm{C}$ by day, $18^{\circ} \mathrm{C}$ by night, to correspond more closely with field conditions. The experiment was initiated on June 21, 1998, and was run for a period of $2 \mathrm{mo}$, until all plants had completed flowering. The experiment was terminated when plants of both races had completed flowering and had reached senescence. Plants were then harvested, separating roots, shoots, and flower heads. Plants were not fertilized during the experiment.

Responses of five variables to the watering treatments were recorded for each pot: survivorship, days to flowering, root and shoot dry mass (used to derive total dry mass and root/ shoot dry mass ratio), and a measure of reproductive fitness, number of flower heads. Shoot and root dry mass were determined after drying at $80^{\circ} \mathrm{C}$ for $24 \mathrm{~h}$ in a forced-draft oven. The values obtained for each pot were used for all subsequent analysis.

\section{Data Analysis}

Tests for normality and homogeneity of variance indicated that no special transformations of the data were needed. Statistical analyses of the effects of race, treatment, and race $\times$ treatment interaction on the measured response variables were conducted using two-way ANOVA implemented in SYSTAT version 10 (SPSS, Chicago). Reaction norm plots were produced to assist in visualizing responses to the different watering treatments, and Tukey's test was used to compare treatment means of the two races for each phenotypic variable. To further test for differences between the two races in survivorship, Kaplan-Meier Survival Analysis (SPSS, Chicago) was conducted for each treatment with race as the predictor variable. In order to examine the possible effects of correlation among phenotypic variables on observed trends, we examined Pearson correlation coefficients among traits for each race within each watering treatment.

\section{Results}

Except for survival, which was high throughout the experiment, all plant growth variables showed significant $(P<$ 0.05 ) race effects (table 1 ), indicating that the races are differentiated in the measured traits. Race A plants were generally larger, allocated relatively more biomass to roots, and flowered later than race $\mathrm{C}$ plants. Race A plants also produced fewer flower heads, especially under medium and low watering treatments (fig. 1).

All variables but survivorship also showed plasticity in response to the watering treatments, and trends were mostly similar for the two races (table 1 ). Both races responded to more severe water restriction by shifting their first flowering earlier, by accumulating less biomass, and allocating relatively more of their biomass to roots (fig. 1). Mortality was low during the course of the experiment, with the highest mortality found in the low watering treatment for both races (three for race A; two for race C). Kaplan-Meier Survival Analysis indicates that the races do not differ $(P>0.05)$ in survivorship in any of the watering treatments.

Only number of flower heads showed a significant race $x$ treatment interaction, indicating that the races are differentiated in their plastic response for this trait (table 1). The two races show nonparallel reaction norms for number of flower heads, with race $\mathrm{C}$ producing significantly greater number of flower heads than race $\mathrm{A}$ under the low watering treatment (fig. 1).

Correlations among phenotypic variables were mostly nonsignificant. Significant Pearson correlation coefficients were detected only between root/shoot dry mass ratio and total mass for race $\mathrm{A}$ in the low watering treatment and for race $\mathrm{C}$ in the medium watering treatment.

\section{Discussion}

The patterns observed in the reaction norms, along with knowledge of the environmental conditions under which the 

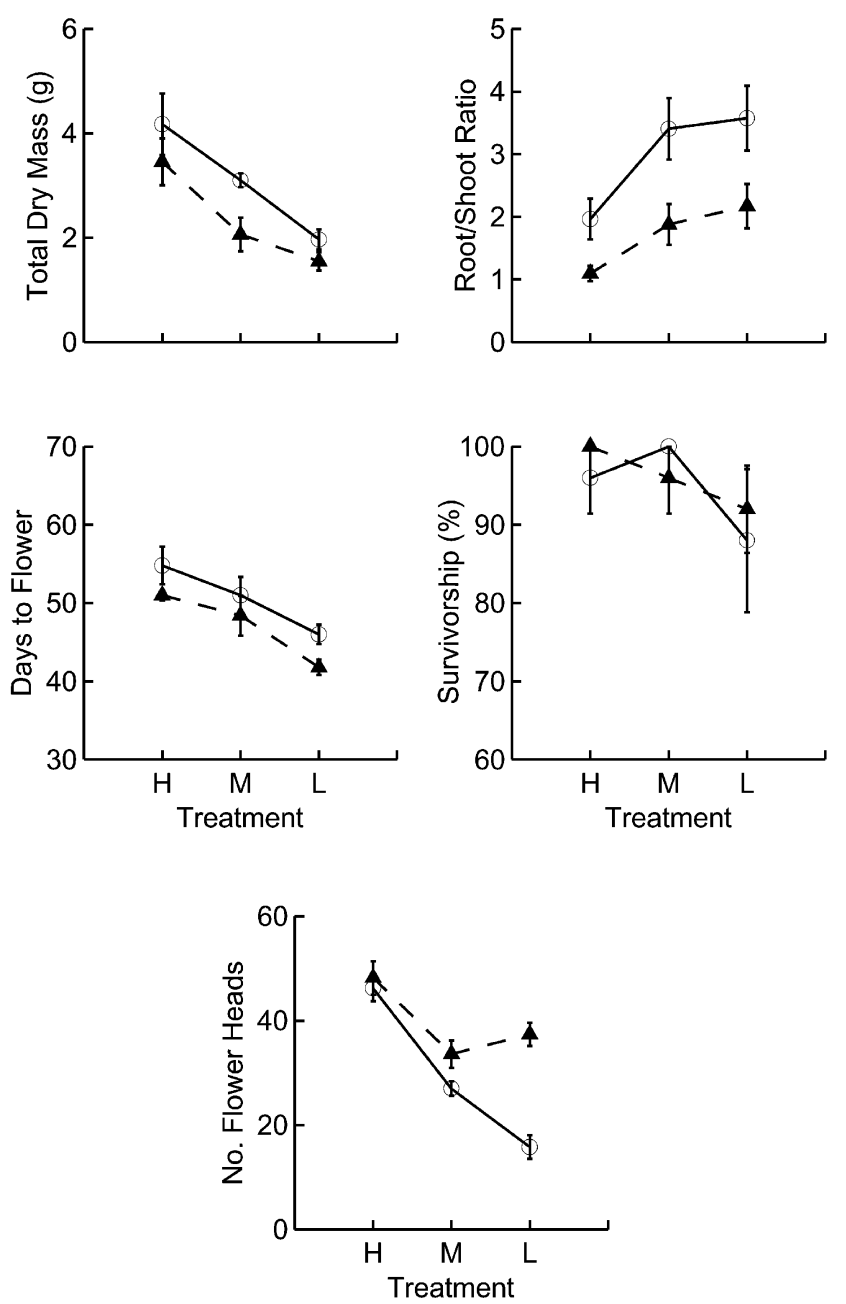

Fig. 1 Reaction norm plots for the two races of Lasthenia californica grown under high $(H)$, medium $(M)$, and low $(L)$ watering treatments. Circles represent race A; triangles represent race C. Values plotted are means and standard errors. Number of flower heads was the only variable with a highly significant $(P<0.001)$ race $x$ treatment interaction effect.

two races grow, indicate a straightforward interpretation of the results of this study. We observed that under low watering treatments, both race $\mathrm{A}$ and race $\mathrm{C}$ plants achieve higher root/ shoot ratios and tend to flower earlier. However, in race A, these phenotypic shifts are associated with a decrease in reproductive output. Race C plants, however, do not sacrifice flower production under low watering treatments (fig. 1). These results indicate that race $\mathrm{C}$ plants are adapted to tolerate drought conditions; they are able to maintain their reproductive fitness under low water availability. Because the phenotype of race $\mathrm{A}$ is affected by drought, reproductive fitness declines, as we would predict for plants that rarely experience drought in their natural environment.

Because this experiment was performed on seed collected from the wild, some of the differences we observed may result, in part, from maternal effects (Mousseau and Fox 1998; but see Lawrence 1964; Thomas 1967; Roach and Wulff 1987 for exceptions). However, these effects are likely minimized by our attempts to sample seeds from throughout the range of microhabitats present at Jasper Ridge. Furthermore, all areas of the ridge, including where race $\mathrm{A}$ is found, dry out during seed set and maturation, when maternal effects are most likely to be strongest (Roach and Wulff 1987). Maternal effects are also most likely to influence seedling characteristics and to diminish over time (Hayward and Nsowah 1969; Thomas 1969; Schmitt and Antonovics 1986), and our variables were all measured on adult plants. Hence, we assume in our discussion of results that maternal influence is either minimal or uniform in its effect on the two races.

The relationship between phenotype and fitness is mitigated by the environment in which organisms occur; thus, it is critical to attempt to relate phenotypic variation and variation in fitness to the environmental conditions experienced in nature. In this study, the responses that we have observed to varying levels of water availability can clearly be related to the ecology of the two races of Lasthenia californica at Jasper Ridge and can be extended to the conditions experienced throughout the species' range.

The two races of L. californica occur in distinct sets of habitats that can be classified on the basis of water availability and ionic stresses (Rajakaruna and Bohm 1999). Race A occupies edaphically extreme environments, occurring primarily on coastal bluffs, vernal pools, alkaline fields, serpentine outcrops, and salt flats. Soils in these environments are generally high in potentially toxic cations, such as sodium and magnesium as well as heavy metals, and low in essential nutrients. Although the soils in these environments are ionically harsh, the percent clay content is generally high (range $7.42 \%-41.3 \%$ for 13 race A populations; Rajakaruna and Bohm 1999), increasing the water-holding capacity of the soil. Race A plants are often found restricted to moist or even saturated soils in such environments.

In contrast, race $\mathrm{C}$ populations are found in more ionically "benign" inland environments, along roadsides, in rocky open fields, and pastures, where the soils are not unusually high in potentially toxic elements. The soils found in these environments are, however, sandy and shallow (range for percent clay content $5.18 \%-23.3 \%$ for nine race C populations; Rajakaruna and Bohm 1999), drying out early in the growing season.

The conditions at Jasper Ridge mirror the trends seen across the range of the species, with the two races again occupying distinct microhabitats; race A occupies the wet (relative water content $/ 100 \mathrm{~g}$ soil ranges from 26.6-49.6; percent clay content, $33.5 \%-45.8 \%$ ) yet ionically harsh soils at the bottom of the ridge, while race $\mathrm{C}$ occupies the fast-drying (relative water content $/ 100 \mathrm{~g}$ soil ranges from 17.6-32.5; percent clay content, $21.3 \%-38.4 \%$ ) yet ionically less stressful upper reaches (Rajakaruna and Bohm 1999). The relative water content for soils at Jasper Ridge (Rajakaruna and Bohm 1999) was measured $2 \mathrm{~d}$ after a rain in April 1996 and indicates the approximate water content at field capacity, clearly indicating the greater water-holding capacity of the ridge bottom soils.

The significantly higher root/shoot ratios observed in race A plants in this experiment are typical of plants found under nutrient-poor and edaphically harsh environments (Kaufmann 1972; Kramer 1980; Crick and Grime 1987; Grime 1994). The combination of higher root/shoot ratios and delayed 
growth relative to race $\mathrm{C}$ plants indicates that race A plants are well adapted to growing under nutrient poor and ionically stressed conditions (Parsons 1968). The significantly lower reproductive output under the low watering treatment may indicate that race A plants are not well adapted to growing under extended drought conditions. Such declines in reproductive effort in response to water stress have been shown for other drought-intolerant herbaceous annuals (Aronson et al. 1993).

Race C plants have a more restricted regional distribution and, at Jasper Ridge, occupy soils that are drier than those where race $\mathrm{A}$ is found (Rajakaruna and Bohm 1999). The faster growth to reproductive maturity observed under the low watering treatment in our experiment is consistent with observations at Jasper Ridge. In the field, race $\mathrm{C}$ plants are often past anthesis when race A plants begin flowering. Race $\mathrm{C}$ appears to be avoiding extreme water stress by completing its life cycle faster, using a strategy often referred to as phenological escape (Mulroy and Rundle 1977; Fitter and Hay 1987). This strategy has been documented in many other herbaceous annuals found growing in dry habitats (Monson and Szarek 1981; Fox 1990; Aronson et al. 1992). Our experiment also reveals that race $\mathrm{C}$ plants allocate relatively more of their biomass to reproduction under water stress, which is again consistent with a strategy employed by drought-tolerant herbaceous species (Baker 1972; Gaines et al. 1974; Monson and Szarek 1981; Aronson et al. 1992, 1993; Sultan and Bazzaz 1993). Thus, race $C$ is able to both avoid and tolerate drought.

Race A plants have broader edaphic tolerances than race $\mathrm{C}$ plants. An examination of soil variables from Jasper Ridge and other sites (Rajakaruna and Bohm 1999) indicates that race A appears to be an ecological "generalist" with respect to many soil features, showing broad tolerance to many edaphic variables measured, including those variables directly associated with soil moisture content. Race C plants, on the other hand, show a restricted tolerance with respect to ionic and moisture conditions, indicating that the responses we see in race $\mathrm{C}$ may reflect ecological "specialization" with respect to these traits. However, it should be noted that the trend observed here, where the putative ecological specialist (race C) displays apparently adaptive plasticity, runs counter to the predictions that "specialists" evolve via ecotypic differentiation (Futuyama and Moreno 1988; Sultan 1995). Further studies, using several populations of the two races, are required to conclude whether responses we see in the two races with respect to water stress reflect adaptive phenotypic plasticity or ecotypic divergence via constitutive traits (see Sultan et al. 1998). The fact that we have detected plasticity in most of the phenotypic traits measured and variation for plasticity in flower production, our estimate of fitness, indicates to us, however, that a hypothesis of adaptive differentiation is reasonable. As such, we intend to build on these results and seek evidence of significant differences in the direction and intensity of selection in further experiments.

\section{Acknowledgments}

We thank Ji Yong Yang for assistance in the field; Nona Chiariello and the administrative staff of the Jasper Ridge Biological Preserve for allowing the collection of cypselae and for providing accommodation during our studies; Massimo Pigliucci, Michael Whitlock, Anne Worley, and four anonymous reviewers for advice and useful comments on the manuscript; and the Natural Sciences and Engineering Research Council (Canada) for financial support.

\section{Literature Cited}

Ackerly DD, CA Knight, SB Weiss, K Barton, KP Starmer 2002 Leaf size, specific leaf area and microhabitat distribution of chaparral woody plants: contrasting patterns in species level and community level analyses. Oecologia 130:449-457.

Aronson J, J Kigel, A Shmida 1992 Adaptive phenology of desert and Mediterranean populations of annual plants grown with or without water stress. Oecologia 89:17-26.

1993 Reproductive allocation strategies in desert and Mediterranean populations of annual plants grown with or without water stress. Oceologia 93:336-342.

Baker AJM 1972 Seed weight in relation to environmental conditions in California. Ecology 53:997-1010.

Baker AJM, J Proctor, RD Reeves 1992 The vegetation of ultramafic (serpentine) soils. Proceedings of the First International Conference on Serpentine Ecology. Intercept, Hampshire. 509 pp.

Bohm BA, A Herring, KW Nicholls, LR Bohm, R Ornduff 1989 A six-year study of flavonoid distribution in a population of Lasthenia californica (Asteraceae). Am I Bot 76:157-163.

Chan R, BG Baldwin, R Ornduff 2002 Cryptic goldfields: a molecular phylogenetic re-investigation of Lasthenia californica sensu lato and close relatives (Compositae: Heliantheae sensu lato). Am I Bot 89: 1103-1112.

Chiariello NR 1989 Phenology of California grasslands. Pages 47-58 in LF Huenneke, HA Mooney, eds. Grassland structure and function: California annual grassland. Kluwer, Dordrecht.

Clegg MT, RW Allard 1972 Patterns of genetic differentiation in the slender wild oat species Avena barbata. Proc Natl Acad Sci USA 69:1820-1824.

Crick JC, JP Grime 1987 Morphological plasticity and mineral nutrient capture in two herbaceous species of contrasted ecology. New Phvtol 107:403-414.

Desrochers AM, BA Bohm 1993 Flavonoid variation in Lasthenia californica. Biochem Syst Ecol 21:449-453.

1995 Biosystematic study of Lasthenia californica (Asteraceae). Syst Bot 20:65-84.

Dudley SA 1996 a Differing selection on plant physiological traits in response to environmental water availability: a test of adaptive hypothesis. Evolution 50:92-102.

$1996 b$ The response to differing selection on plant physiological traits: evidence for local adaptation. Evolution 50:103-110.

Farris MA 1987 Natural selection on the plant-water relations of Cleome serrulata growing along natural moisture gradients. Oecologia 72:434-439.

- 1988 Quantitative genetic variation and natural selection in Cleome serrulata growing along a mild soil moisture gradient. $\underline{\text { Can }}$ I Bot 66:1870-1876.

Fitter AH, RKM Hay 1987 Environmental physiology of plants. 2d ed. Academic Press, London. 423 pp.

Fox GA 1990 Drought and the evolution of flowering time in desert annuals. Am I Bot 77:1508-1518.

Futuyama DJ, G Moreno 1988 The evolution of ecological specialization. Annu Rev Ecol Syst 19:207-233. 
Gaines MS, KJ Vogt, JL Hamrick, J Caldwell 1974 Reproductive strategies and growth patterns in sunflowers (Helianthus). Am Nat 108:889-895.

Gaudet CL, PA Keddy 1995 Competitive performance and species distribution in shoreline plant communities: a comparative approach. Ecology 76:280-291.

Girdler EB 1999 Resource-based community structure in an annual serpentine grassland. $\mathrm{PhD}$ diss. Princeton University.

Grime JP 1994 The role of plasticity in exploiting environmental heterogeneity. Pages 1-21 in MM Caldwell, RW Pearcy, eds. Exploitation of environmental heterogeneity by plants. Academic Press, New York.

Hamrick JL, RW Allard 1972 Microgeographical variation in allozyme frequencies in Avena barbata. Proc Natl Acad Sci USA 69: 2100-2104.

Hamrick JL, LR Holden 1979 Influence of microhabitat heterogeneity on gene frequency distribution and gametic phase disequilibrium in Avena barbata. Evolution 33:521-533.

Hayward MD, GF Nsowah 1969 The genetic organization of natural populations of Lolium perenne. IV. Variation within populations. Heredity 24:521-528.

Hughes R, K Bachmann, N Smirnoff, MR Macnair 2001 The role of drought tolerance in serpentine tolerance in the Mimulus guttatus Fischer ex DC. complex. S Afr J Sci 97:581-586.

Kaufmann MR 1972 Water deficits and reproductive growth. Pages 91-124 in TT Kozlowski, ed. Water deficits and plant growth. Academic Press, San Diego, Calif.

Kramer PJ 1980 Drought, stress, and the origin of adaptations. Pages 7-20 in NC Turner, PJ Kramer, eds. Adaptation of plants to water and high temperature stress. Wiley, New York.

Kruckeberg AR 1984 California serpentines: flora, vegetation, geology, soils, and management problems. University of California Press, Berkeley. 180 pp.

Lawrence CW 1964 Genetic studies on wild populations of Melandrium. III. Heredity 19:1-19.

Marshall DL, DA Levin, NL Fowler 1986 Plasticity of yield components in response to stress in Sesbania macrocarpa and Sesbania vesicaria (Leguminosae). Am Nat 127:508-521.

Monson RK, SR Szarek 1981 Life cycle characteristics of Machaeranthera gracilis (Compositae) in desert habitats. Oecologia 50: $50-55$.

Mousseau TA, CW Fox 1998 The adaptive significance of maternal effects. Trends Ecol Evol 13:403-407.

Mulroy TW, PW Rundle 1977 Annual plants: adaptations to desert environments. BioScience 21:109-114.

Ornduff R 1993 Lasthenia. Pages 298-300 in JC Hickman, ed. The Jepson manual: higher plants of California. University of California Press, Berkeley.

Parsons RF 1968 The significance of growth-rate comparisons for plant ecology. Am Nat 102:595-597.
Proctor J 1999 Toxins, nutrient shortages and droughts: the serpentine challenge. Trends Ecol Evol 14:334-335.

Proctor J, SRJ Woodell 1975 The ecology of serpentine soils. Adv Ecol Res 9:255-366.

Rajakaruna N, BG Baldwin, R Chan, AM Desrochers, BA Bohm, J Whitton In press Edaphic races and phylogenetic taxa in the Lasthenia californica complex (Asteraceae: Heliantheae): an hypothesis of parallel evolution. Mol Ecol.

Rajakaruna N, BA Bohm 1999 The edaphic factor and patterns of variation in Lasthenia californica (Asteraceae). Am I Bot 86: 1576-1596.

Rajakaruna N, MY Siddiqi, J Whitton, BA Bohm, ADM Glass 2003 Differential responses to $\mathrm{Na}^{+} / \mathrm{K}^{+}$and $\mathrm{CA}^{2+} / \mathrm{MG}^{2+}$ in two edaphic races of the Lasthenia californica complex (Asteraceae): a case for parallel evolution of physiological traits. New Phytol 157:93-103.

Roach DA, RD Wulff 1987 Maternal effects in plants. Annu Rev Ecol Syst 18:209-235.

Roy J, HA Mooney 1982 Physiological adaptation and plasticity to water stress of coastal and desert populations of Heliotropium curassavicum L. Oecologia 52:370-375.

Schmitt J 1993 Reaction norms of morphological and life-history traits to light availability in Impatiens capensis. Evolution 47: 1654-1668.

Schmitt J, J Antonovics 1986 Experimental studies of the evolutionary significance of sexual reproduction. III. Maternal and paternal effects during seedling establishment. Evolution 40:830-836.

Schmitt J, J Niles, RD Wulff 1992 Norms of reaction of seed traits to maternal environments in Plantago lanceolata. Am Nat 139: 451-466.

Sultan SE 1995 Phenotypic plasticity and plant adaptation. Acta Bot Neerl 44:363-383.

2001 Phenotypic plasticity for fitness components in Polygonum species of contrasting ecological breadth. Ecology 82: 328-343.

Sultan SE, FA Bazzaz 1993 Phenotypic plasticity in Polygonum persicaria. II. Norms of reaction to soil moisture and the maintenance of genetic diversity. Evolution 47:1032-1049.

Sultan SE, AM Wilczek, SD Hann, BJ Brosi 1998 Contrasting ecological breadth of co-occurring annual Polygonum species. IEcol 86:363-383.

Thomas RL 1967 Inter-population variation in perennial ryegrass. 1. Population means. Heredity 22:481-498.

1969 Inter-population variation in perennial ryegrass. 3. Interaction of heritable and environmental variation. Heredity 24: 91-100.

Wade MJ, S Kalisz 1990 The causes of natural selection. Evolution 44:1947-1955.

Zhang J, MJ Lechowicz 1994 Correlation between time of flowering and phenotypic plasticity in Arabidopsis thaliana. Am I Bot 81: $1336-1342$ 